\title{
Review
}

\section{A review of non iterative friction factor correlations for the calculation of pressure drop in pipes}

\author{
Mustafa Asker, Oguz Emrah Turgut * , Mustafa Turhan Coban \\ Ege University, School of Engineering, Department of Mechanical Engineering, Bornova, İzmir - Turkey \\ * Corresponding author: oeturgut@hotmail.com
}

\begin{abstract}
Pressure drop in pipes can be calculated by using the Darcy-Weisbach formula. In order to use this formula, the Darcy friction factor should be known. The best approximation to the Darcy friction factor for turbulent flow is given by the Colebrook-White equation. This equation can only be solved by numerical root finding methods. There are several other approximate correlations to the Darcy friction factor with some relative error compared to the Colebrook-White equation. It was found that in some of these correlations, the percentage error is so small that they can be used directly in place of the Colebrook equation. In this study, a review of several friction factor correlations is performed. Relative error of these correlations is re-evaluated against the Reynolds number for a different value of relative pipe roughness. Also statistical analyses will be given for each correlation.
\end{abstract}

Keywords: Colebrook equation, Darcy -Weisbach pressure drop formula, friction factor

\section{Introduction}

The pressure loss in pipe flow is calculated by using the Darcy-Weisbach equation. The equation is given as:

$\Delta P=f \frac{L}{D} \rho \frac{V^{2}}{2}$

In equation (1) $\Delta P$ is the pressure drop, $f$ is the Darcy friction factor, $\rho$ is the density of the fluid, $D$ is the hydraulic diameter of the pipe and $V$ is the average velocity. The Darcy friction factor $(f)$ depends on the flow regime. For a fully developed laminar flow (Reynolds number $R e<2300$ ) the friction factor can be determined from the Hagen-Poiseuille equation as:

$f=\frac{64}{\operatorname{Re}}$

Where, Re is the Reynolds number. The definition of the Re number can be given as follows:

$\operatorname{Re}=\frac{\rho V D}{\mu}$

Where $\rho$ is the density and $\mu$ is the dynamic viscosity of the fluid. In equation (2) the friction factor changes inversely with the Reynolds number. For the transition region $(2300 \leq R e \leq 4000)$ and the turbulent region $(R e \geq$ 4000 ) in smooth as well as rough pipe the friction factor can be described by Colebrook-White equation (White 1998). Some researchers have made alternative correlations to estimate the friction factor in pipes. Clamond (2009) presented a strong, fast and accurate algorithm for solving the Colebrook-like equations. He used the Lambert W-function algorithm which was efficient for the whole range of parameters involved in the Colebrook equation. A review for some explicit approximation of the Colebrook's equation was made by (Genić et al. 2011). They found that the equation of Zigrang \& Sylvester (1982) provides the most accurate value of the friction factor. Ghanbari et al. (2011) developed a friction factor correlation based on the nonlinear multi variable surface fitting tool in MATLAB. The equation correlates the friction factor to the Reynolds number and the relative roughness by means of simple logarithmic and exponential functions. They used statistical analysis to test and validate their model. Samadianfard (2012) used the potential of a genetic programming based technique to calculate the friction factor in turbulent flow. He compared his model with commonly used explicit models for the Colebrook-White equation. He revealed that by using genetic expression programming the friction factor can be identified precisely. Winning \& Coole (2013) compared the accuracy and computation efficiency of twelve explicit friction factor equations.

The aim of this work is to make a comprehensive review of several friction factor correlations and compare the relative error of these correlations in order to used them directly in the place of the Colebrook-White equation during the calculation of pressure drop in pipes.

\section{Friction Factor Correlations}

\subsection{Colebrook-White equation}

The Colebrook-White equation can be defined as follows (Colebrook \& White 1937).

$\frac{1}{\sqrt{f}}=-2 \log _{10}\left[\frac{(\varepsilon / D)}{3.7}+\frac{2.51}{\operatorname{Re} \sqrt{f}}\right]$

Where $\varepsilon / D$ is the relative roughness which is the ratio of the mean height of roughness of the pipe to the pipe diameter. As seen from equation (4) the friction factor is a function of the Reynolds number and pipe roughness $(\epsilon)$. The Colebrook-White equation cannot be solved directly due to its implicit form as the value of $f$ appears 
on both side of the equation. In order to solve equation (4) a numerical root finding method, for example the Newton-Raphson method can be used.

$$
\text { Assume } X=\frac{1}{\sqrt{f}}
$$

$f(X)=X+2 \log _{10}\left[\frac{(\varepsilon / D)}{3.7}+\frac{2.51}{\operatorname{Re}} X\right]$

$\frac{d f(X)}{d X}=1+2 \frac{(2.51 / \mathrm{Re})}{\left[\frac{(\varepsilon / D)}{3.7}+\frac{2.51}{\operatorname{Re}} X\right]}$

$$
X_{k+1}=X_{k}-\frac{[f(X)]_{k}}{[d f(X) / d X]_{k}} \quad k=0, \ldots \ldots, n
$$

Equation (8) is required to be solved iteratively. In order to solve the equation, an initial guess is needed. If the value of the first guess diverges from the exact value, the equation may converge very slowly or may not converge at all. In order to find the first guess value, one of the approximate formulas given below can be used. In this work the Haaland (1983) equation is used to guess the first estimation value for the Colebrook-White equation. The result of some of the approximation equations listed is very close to the result obtained from the Colebrook-White equation. When the error level of the new equation is relatively small, the requirement of using the Colebrook-White equation can be eliminated altogether. A similar equation can be easily computed by using a simpler computational environment such as programmable calculators or spreadsheet programs such as MS Excel. Some of the Colebrook-White equation approximation formulas are listed below according to their years.

\subsection{Moody correlation}

Moody (1947) developed a relationship that is valid for all ranges of the Reynolds numbers and the relative roughness' as follows.

$$
f=5.5 \times 10^{-3}\left[1+\left(2 \times 10^{4}(\varepsilon / D)+\frac{10^{6}}{\mathrm{Re}}\right)^{1 / 3}\right]
$$

\subsection{Altshul correlation}

Altshul (1952) which is cited in Genić et al. (2011) gave a friction factor correlation presented as Eq. (10).

$$
f=0.11\left(\frac{68}{\operatorname{Re}}+(\varepsilon / D)\right)^{0.25}
$$

\subsection{Wood correlation}

Correlation proposed by Wood (1966). Its validation region extends for $\operatorname{Re}>10000$ and $10^{-5}<(\varepsilon / D)<0.04$.

$f=a+b \operatorname{Re}^{-c}$

where

$a=0.53(\varepsilon / D)+0.094(\varepsilon / D)^{0.225}$

$b=88(\varepsilon / D)^{0.44}$

$c=1.62(\varepsilon / D)^{0.134}$

\subsection{Churchill correlation}

Correlation proposed by Churchill (1973) which is valid only for the turbulent regime and it is similar to the Swamee \& Jain correlation (1976).

$\frac{1}{\sqrt{f}}=-2 \cdot \log _{10}\left(\frac{(\varepsilon / D)}{3.71}+\left(\frac{7}{\operatorname{Re}}\right)^{0.9}\right)$

\subsection{Eck correlation}

Correlation proposed by Eck (1973) defined as

$\frac{1}{\sqrt{f}}=-2 \cdot \log _{10}\left(\frac{(\varepsilon / D)}{3.71}+\frac{15}{\mathrm{Re}}\right)$

\subsection{Jain correlation}

Correlation proposed by Jain (1976) described as

$\frac{1}{\sqrt{f}}=-2 . \log _{10}\left(\frac{(\varepsilon / D)}{3.715}+\left(\frac{6.943}{\operatorname{Re}}\right)^{0.9}\right)$

\subsection{Swamee-Jain correlation}

Swamee \& Jain (1976) has developed the following equation to the Darcy friction factor correlation. Its validation region extends for $5000>\operatorname{Re}>10^{7}$ and $0.00004<$ $(\varepsilon / D)_{<0.05}$

$f=\frac{0.25}{A^{2}}$

where

$A=\log _{10}\left(\frac{(\varepsilon / D)}{3.7}+\frac{5.74}{\operatorname{Re}^{0.9}}\right)$

\subsection{Churchill correlation (1977)}

Correlation proposed by Churchill (1977) which is valid for all ranges of the Reynolds numbers.

$f=\left[\left(\frac{64}{\operatorname{Re}}\right)^{12}+(A+B)^{-3 / 2}\right]^{1 / 12}$

where

$A=\left[0.8687 \ln \frac{1}{\frac{0.883(\ln \operatorname{Re})^{1.282}}{\operatorname{Re}^{1.007}}+0.27\left(\frac{\varepsilon}{D}\right)+\frac{110(\varepsilon / D)}{\operatorname{Re}}}\right]^{16}$

$B=\left(\frac{13269}{\operatorname{Re}}\right)^{16}$

\subsection{Chen correlation}

Chen (1979) proposed the following equation for the friction factor covering all the ranges of the Reynolds number and the relative roughness'.

$\frac{1}{\sqrt{f}}=-2 \log _{10}\left[\left(\frac{(\varepsilon / D)}{3.7065}\right)-\frac{5.0452 A}{\operatorname{Re}}\right]$

Where

$$
A=\log _{10}\left(\frac{(\varepsilon / D)^{1.1098}}{2.8257}+\frac{5.8506}{\mathrm{Re}^{0.8981}}\right)
$$




\subsection{Round correlation}

Correlation proposed by Round (1980). Its validation region extends for $4 \times 10^{3}<R e<4 \times 10^{8}$, and $\varepsilon$ between 0 and 0.05 .

$$
f=[-1.8 \log (0.135(\varepsilon / D)+6.5 / \operatorname{Re})]^{-2}
$$

\subsection{Shacham correlation}

Correlation proposed by Shacham (1980) as:

$f=\left[-2 \log _{10}\left(\frac{(\varepsilon / D)}{3.7}-\frac{5.02}{\operatorname{Re}} \log _{10}\left(\frac{(\varepsilon / D)}{3.7}+\frac{14.5}{\operatorname{Re}}\right)\right)\right]^{-2}$

\subsection{Barr correlation}

Barr (1981) gave a friction factor correlation as presented in equation (27).

$\frac{1}{\sqrt{f}}=-2 \log \left(\frac{\varepsilon}{3.7 D}+\frac{5.158 \log (\mathrm{Re} / 7)}{\operatorname{Re}\left(1+\frac{\operatorname{Re}^{0.52}}{29}\left(\frac{\varepsilon}{D}\right)^{0.7}\right)}\right)$

\subsection{Zigrang \& Sylvester correlation}

Zigrang \& Sylvester (1982) developed a relationship that is valid for all ranges of the Reynolds numbers and the relative roughness as follows.

$$
\begin{aligned}
& \frac{1}{\sqrt{f}}=-2 \log _{10}\left[\left(\frac{(\varepsilon / D)}{3.7}\right)-\frac{5.02 B}{\operatorname{Re}}\right] \\
& A=\log _{10}\left(\frac{(\varepsilon / D)}{3.7}+\frac{13}{\operatorname{Re}}\right) \\
& B=\log _{10}\left(\frac{(\varepsilon / D)}{3.7}-\frac{5.02 A}{\operatorname{Re}}\right)
\end{aligned}
$$

\subsection{Haaland correlation}

An approximate equation is shown by Haaland (1983). It is valid for turbulent flow ( $\mathrm{Re}>2300)$.

$$
\frac{1}{\sqrt{f}}=-1.8 \log _{10}\left[\left(\frac{(\varepsilon / D)}{3.7}\right)^{1.11}+\frac{6.9}{\operatorname{Re}}\right]
$$

\subsection{Serghides correlation}

Serghides (1984) equation is an approximation of the implicit Colebrook-White equation. It is valid for all ranges of the Reynolds numbers and the relative roughness' as follows.

$$
\frac{1}{\sqrt{f}}=A-\frac{(B-A)^{2}}{C-2 B+A}
$$

where

$$
\begin{aligned}
& A=-2 \log _{10}\left[\left(\frac{(\varepsilon / D)}{3.7}\right)+\frac{12}{\operatorname{Re}}\right] \\
& B=-2 \log _{10}\left[\left(\frac{(\varepsilon / D)}{3.7}\right)+\frac{2.51 A}{\operatorname{Re}}\right] \\
& C=-2 \log _{10}\left[\left(\frac{(\varepsilon / D)}{3.7}\right)+\frac{2.51 B}{\operatorname{Re}}\right]
\end{aligned}
$$

\subsection{Tsal correlation}

Tsal (1989) developed a relationship that is valid for $4 \times 10^{3}<R e<4 \times 10^{8}$, and $\varepsilon$ between 0 and 0.05 .

$f= \begin{cases}C & \text { if }(\mathrm{C} \geq 0.018) \\ 0.0028+0.85 \mathrm{C} & \text { if }(\mathrm{C}<0.018)\end{cases}$

where

$C=0.11\left(\frac{68}{\operatorname{Re}}+\frac{\varepsilon}{D}\right)^{0.25}$

\subsection{Manadilli correlation}

Manadilli (1997) developed a correlation that is valid for the Reynolds number range that extends from $4 \times 10^{3}$ to $4 \times 10^{8}$ and $\varepsilon$ between 0 and 0.05 .

$f=\left[-2 \log \left(\frac{\varepsilon}{3.70}+\frac{95}{\mathrm{Re}^{0.983}}-\frac{96.82}{\mathrm{Re}}\right)\right]^{-2}$

\subsection{Monzon-Romeo-Royo correlation}

Monzon et al. (2002) developed a relationship that is valid for all ranges of the Reynolds numbers and the relative roughness' as follows.

$\frac{1}{\sqrt{f}}=-2 \log _{10}\left[\left(\frac{(\varepsilon / D)}{3.7065}\right)-\frac{5.0272 B}{\operatorname{Re}}\right]$

$A=\log _{10}\left[\left(\frac{(\varepsilon / D)}{7.7918}\right)^{0.9924}+\left(\frac{5.3326}{208.815+\mathrm{Re}}\right)^{0.9345}\right]$

$B=\log _{10}\left(\frac{(\varepsilon / D)}{3.827}-\frac{4.567 A}{\operatorname{Re}}\right)$

\subsection{Goudar-Sonnad correlation}

Goudar \& Sonnad (2006) developed the following relationship.

$\frac{1}{\sqrt{f}}=0.8686 \ln \left(\frac{0.4587 \mathrm{Re}}{(C-0.31)^{\frac{C}{C+1}}}\right)$

where

$C=0.124 \operatorname{Re} \frac{\varepsilon}{D}+\ln (0.4587 \operatorname{Re})$

\subsection{Buzzelli correlation}

Buzelli (2008) developed a relationship as presented in Eq. (44).

$\frac{1}{\sqrt{f}}=A-\left[\frac{A+2 \log (B / \operatorname{Re})}{1+(2.18 / B)}\right]$

where

$$
\begin{aligned}
& A=\frac{(0.744 \ln (\mathrm{Re})-1.41)}{(1+1.32 \sqrt{\varepsilon / D})} \\
& B=\frac{\varepsilon}{3.7 D} \operatorname{Re}+2.51 A
\end{aligned}
$$

\subsection{Goudar- Sonnad correlation}

Goudar \& Sonnad (2008) equation is an approximation of the implicit Colebrook-White equation. This equation is valid for all ranges of the Reynolds numbers and the relative roughness'. 


$$
\begin{aligned}
& \frac{1}{\sqrt{f}}=a\left[\ln \left(\frac{d}{q}\right)+\delta_{C F A}\right] \\
& \text { where } \\
& a=\frac{2}{\ln (10)} \\
& b=\frac{(\varepsilon / D)}{3.7} \\
& d=\frac{\ln (10)}{5.02} \operatorname{Re} \\
& s=b d+\ln (d) \\
& q=S(s /(s+1)) \\
& g=b d+\ln (d / q) \\
& z=\left(\frac{q}{g}\right) \\
& \delta_{L A A}=\frac{g}{g+1} z \\
& =\delta_{L A}\left(1+\frac{z / 2}{(g+1)^{2}+(z / 3)(2 g-1)}\right)
\end{aligned}
$$

\subsection{Avci and Karagoz correlation}

Correlation proposed by Avci \& Karagoz (2009) is described as.

$$
f=\frac{6.4}{\left[\ln (\mathrm{Re})-\ln \left(1+0.01 \mathrm{Re} \cdot \frac{\varepsilon}{D} \cdot\left(1+10 \times \sqrt{\frac{\varepsilon}{D}}\right)\right)\right]^{2.4}}
$$

\subsection{Papaevangelou correlation}

Papaevangelou et al. (2010) developed the following relationship as presented in equation (58)

$$
f=\frac{0.2479-0.0000947(7-\log \mathrm{Re})^{4}}{\left(\log \left(\frac{\varepsilon}{3.615 D}+\frac{7.366}{\mathrm{Re}^{0.9142}}\right)\right)^{2}}
$$

\subsection{Brkic correlation}

Brkic (2011) developed two types of relationships to calculate the friction factor as follows.

$$
\begin{gathered}
\text { 1. } f=\left[-2 \log \left(10^{-0.4343 S}+(\varepsilon / D) / 3.71\right)\right]^{-2} \\
S=\ln \frac{\operatorname{Re} \text { and }}{1.816 \ln \left(\frac{1.1 \operatorname{Re}}{\ln (1+1.1 \mathrm{Re})}\right)} \\
\text { 2. } f=[-2 \log ((2.18 S / \operatorname{Re})+(\varepsilon / D) / 3.71)]^{-2}
\end{gathered}
$$

\subsection{Fang correlation}

Fang et al. (2011) developed a relationship that is valid for $3 \times 10^{3}<R e<4 \times 10^{8}$, and $\varepsilon$ between 0 and 0.05 . Presented as Eq. (62). $f=1.613\left[\ln \left(0.234(\varepsilon / D)^{1.1007}-\frac{60.525}{\mathrm{Re}^{1.1105}}+\frac{56.291}{\mathrm{Re}^{1.0712}}\right)\right]^{-2}$

\subsection{Ghanbari-Farshad-Rieke's correlation}

Correlation proposed by Ghanbari et al. (2011) is based on data collected from the Moody diagram. The range of applicability of their equation is between the relative roughness of $\varepsilon / D=0.0$ to 0.05 and the Reynolds numbers ranging from 2100 to $10^{8}$.

$f=\left[-1.52 \log \left(\left(\frac{\varepsilon / D}{7.21}\right)^{1.042}+\left(\frac{2.731}{\operatorname{Re}}\right)^{0.9152}\right)\right]^{-2.169}$

\section{Statistical analysis}

In the analysis procedure, the existing correlations are compared with the Colebrook-White equation. Five statistical methods are introduced to test the effectiveness of the correlations for each selected relative roughness. The Reynolds number region is divided into $N$ data nodes. The Colebrook-White and aforementioned friction factors are calculated for each data node. Then the proposed statistical methods are applied for these sets of data. These statistical methods are described in equations (65) to (69) respectively. The results of the statistical comparison are given in Tables 1-4. In order to determine the relative error of all these approximate formulas, relative error of each equation with respect to the Colebrook-White equation is calculated by using the following equation.

Relative error $=\frac{\left(f_{\text {Colebrook-White }}-f_{\text {pred }}\right)}{f_{\text {Colebrook-White }}} \times 100$

The five statistical methods that are used in the comparison can be expressed as follows:

\section{Standard deviation:}

$S D \%=\sqrt{\left[\sum_{i=1}^{N}\left(\frac{f_{\text {pred }, i}-f_{\text {Colebrook }, i}}{f_{\text {Colebrook }, i}}\right)^{2}\right]} \times \frac{100}{N}$

Mean deviation:

$M D \%=\left[\sum_{i=1}^{N}\left|\frac{f_{\text {pred }, i}-f_{\text {Colebrook }, i}}{f_{\text {Colebrook }, i}}\right|\right] \times \frac{100}{N}$

Average deviation

$A D \%=\left[\sum_{i=1}^{N} \frac{f_{\text {pred }, i}-f_{\text {Colebrook }, i}}{f_{\text {Colebrook }, i}}\right] \times \frac{100}{N}$

Maximal positive error (MPE)

Maxerror $^{+}=\max \left(\frac{f_{\text {Colebrook }, i}-f_{\text {pred }, i}}{f_{\text {Colebrook }, i}}\right)$

Maximal negative error (MNE)

Maxerror $^{-}=\max \left(\frac{f_{\text {pred }, i}-f_{\text {Colebrook }, i}}{f_{\text {Colebrook }, i}}\right)$ 


\section{Results}

In this work a comprehensive review for many friction factor correlations that is used in the calculation of pressure drop in pipes are conducted. The variation of relative error against the Reynolds number for different relative roughness $(\varepsilon / D=1 e-2, \varepsilon / D=1 \mathrm{e}-$ $4, \varepsilon / \mathrm{D}=1 \mathrm{e}-6$ and $\varepsilon / \mathrm{D}=1 \mathrm{e}-8)$ are examined. In addition, the statistical comparison for each friction factor correlated with the Colebrook's equation for the mentioned relative roughnesses are implemented and reported in Tables 1-4.

Figure 1 depicts the relative error of the Goudar \& Sonnad (2008) correlation against the Reynolds number for different relative roughnesses. It is observed that, as the Reynolds number increase, the relative error remains below $1 \mathrm{e}-9$ for the relative roughness of $\varepsilon / \mathrm{D}=1 \mathrm{e}-2$, $\varepsilon / \mathrm{D}=1 \mathrm{e}-4, \varepsilon / \mathrm{D}=1 \mathrm{e}-6$ and $\varepsilon / \mathrm{D}=1 \mathrm{e}-8$ so that it's very convenient to utilize this correlation instead of the ColebrookWhite equation.

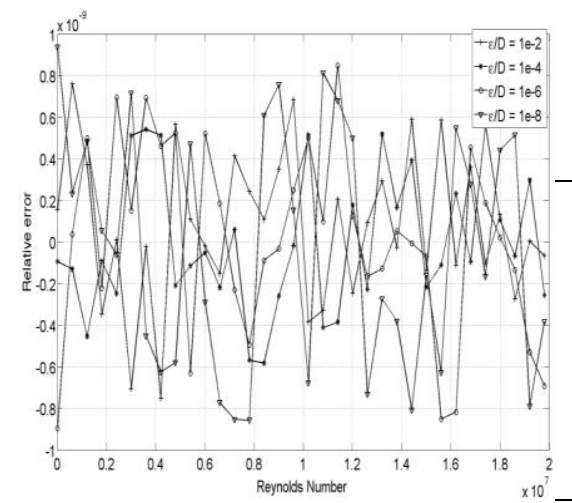

Figure 1. The amount of relative error comparison between the Goudar-Sonnad and Colebrook White equations.

The relative error of the Serghides (1984) and Zigrang \& Sylvester (1982) correlations against the Reynolds number for different relative roughness are shown in Figures 2-3 respectively.

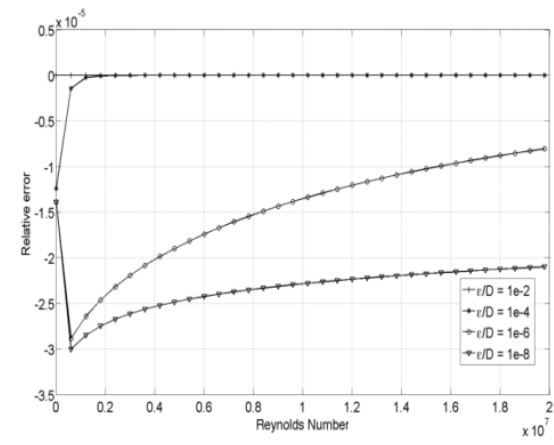

Figure 2. The amount of relative error comparison between the Serghides and Colebrook White equations.
Table 1 provides the statistical analyses for the relative roughness of $1 \mathrm{e}-8$. It is seen that the best results are performed by the Goudar \& Sonnad (2008), Serghides (1984) and Buzzelli (2008) correlations while the Wood (1966), Altshul (1952) and Tsal (1989) correlations give the worst results with a standard deviation of $2.3426 \%, 1.4659 \%$ and $0.3079 \%$ respectively.

Table 1. Statistical comparison for $\varepsilon / D=1 e-8$

\begin{tabular}{|c|c|c|c|c|c|}
\hline Correlation & $\begin{array}{l}\% \\
\text { Average } \\
\text { deviation }\end{array}$ & $\begin{array}{l}\% \\
\text { Standard } \\
\text { deviation }\end{array}$ & $\begin{array}{l}\% \\
\text { Mean } \\
\text { deviation }\end{array}$ & MNE & MPE \\
\hline Moody (1947) & -0.9894 & 0.1300 & 2.0927 & 0.0247 & 0.0561 \\
\hline Altshul (1952) & -28.493 & 1.4659 & 28.508 & 0.0228 & 0.3564 \\
\hline Wood (1966) & -46.7391 & 2.3426 & 46.7391 & -0.4372 & 0.7086 \\
\hline Churchill (1973) & 0.4943 & 0.0298 & 0.5470 & 0.0085 & 0.0061 \\
\hline $\operatorname{Eck}(1973)$ & -7.8183 & 0.3921 & 7.8259 & 0.0151 & 0.0819 \\
\hline Jain(1976) & 0.3821 & 0.0258 & 0.4682 & 0.0075 & 0.0078 \\
\hline Swamee-Jain (1976) & 0.3916 & 0.0257 & 0.4664 & 0.0076 & 0.0070 \\
\hline Churchill (1977) & -0.0480 & 0.0010 & 0.0480 & $-4.4 \mathrm{e}-4$ & $7.13 e-4$ \\
\hline Chen (1979) & -0.0116 & 0.0014 & 0.0244 & $8.827 e-4$ & $6.2 \mathrm{e}-4$ \\
\hline Round (1980) & -0.6038 & 0.0367 & 0.6038 & -0.0014 & 0.0217 \\
\hline Shacham(1980) & 0.7833 & 0.01753 & 0.7834 & 0.0081 & $7.03 e-4$ \\
\hline Barr (1981) & -0.03873 & 0.0023 & 0.0440 & $7.10 \mathrm{e}-4$ & $6.73 e-4$ \\
\hline Zigrang-Sylvester (1982) & -0.0737 & 0.0037 & 0.0737 & $-6.478 e-4$ & 0.0011 \\
\hline Haaland (1983) & 0.2364 & 0.0207 & 0.3686 & 0.0061 & 0.0091 \\
\hline Serghides (1984) & -0.0023 & $1.185 \mathrm{e}-4$ & 0.0023 & $-1.390 e-5$ & $3.13 e-5$ \\
\hline Tsal (1989) & -5.998 & 0.3079 & 6.0126 & 0.0228 & 0.0719 \\
\hline Manadilli (1997) & 0.1262 & 0.0065 & 0.1262 & 0.0016 & $8.25 \mathrm{e}-6$ \\
\hline Monzon et al. (2002) & 0.0484 & 0.0024 & 0.0484 & $5.071 \mathrm{e}-4$ & $-4.36 \mathrm{e}-4$ \\
\hline Goudar-Sonnad (2006) & -0.9235 & 0.0463 & 0.9235 & -0.0085 & 0.0171 \\
\hline Buzzelli (2008) & 0.0173 & $8.654 \mathrm{e}-4$ & 0.0173 & $2.657 e-4$ & $-1.67 e-4$ \\
\hline Goudar-Sonnad (2008) & $-1.9270 \mathrm{e}-9$ & $2.588 \mathrm{e}-9$ & $4.446 \mathrm{e}-8$ & $9.750 \mathrm{e}-10$ & $9.48 \mathrm{e}-10$ \\
\hline Avci and Karagöz(2009) & 0.1752 & 0.0144 & 0.1812 & 0.0098 & $2.48 \mathrm{e}-4$ \\
\hline Papaevangelou (2010) & -0.0469 & 0.0051 & 0.0810 & $8.328 \mathrm{e}-4$ & 0.0021 \\
\hline Brkic1 (2011) & 0.1722 & 0.0087 & 0.1722 & 0.0048 & -0.0015 \\
\hline Brkic2 (2011) & -2.1046 & 0.1054 & 2.1046 & -0.0198 & 0.0315 \\
\hline Fang (2011) & 0.3912 & 0.019 & 0.3912 & 0.0041 & -0.0028 \\
\hline Ghanbari et al. (2011) & 1.8018 & 0.0405 & 1.8018 & 0.0195 & -0.0052 \\
\hline
\end{tabular}

Table 2 provides the statistical analyses for the relative roughness of $1 \mathrm{e}-6$. It is seen that Goudar \& Sonnad (2008) Serghides (1984) and Buzzelli (2008) correlations with a standard deviation of $2.42 \mathrm{e}-9 \%, 8.08 \mathrm{e}-5 \%$ and $6.07 \mathrm{e}-$ $4 \%$ correspondingly agrees with the results of the Colebrook-White correlation. On the other hand, the Wood (1966), Altshul (1952) and Tsal (1989) correlations do not give accurate results for the mentioned relative roughness value.

Table 2. Statistical comparison for $\varepsilon / D=1 e-6$

\begin{tabular}{llllll} 
Correlation & $\begin{array}{l}\text { \% } \\
\text { Average } \\
\text { deviation }\end{array}$ & $\begin{array}{l}\text { \% } \\
\text { Standard } \\
\text { deviation }\end{array}$ & $\begin{array}{l}\text { \% } \\
\text { Mean } \\
\text { deviation }\end{array}$ & MNE & MPE \\
\hline Moody (1947) & -0.4494 & 0.1321 & 2.2083 & 0.0324 & 0.0552 \\
Altshul (1952) & -27.100 & 1.3902 & 27.115 & 0.0228 & 0.3301 \\
Wood (1966) & -8.8311 & 0.4523 & 8.8311 & -0.0695 & 0.2372 \\
Churchill (1973) & 0.4943 & 0.0298 & 0.5470 & 0.0085 & 0.0061 \\
Eck(1973) & -7.8183 & 0.3921 & 7.8259 & 0.0151 & 0.0819 \\
Jain(1976) & 0.3821 & 0.0258 & 0.4682 & 0.0075 & 0.0078 \\
Swamee-Jain (1976) & 0.4398 & 0.0278 & 0.5085 & 0.0081 & 0.0070 \\
Churchill (1977) & 0.0427 & 0.0013 & 0.0526 & $7.08 \mathrm{e}-4$ & 0.0010 \\
Chen (1979) & 0.0515 & 0.0026 & 0.0518 & $9.06 \mathrm{e}-4$ & 6.1787 \\
Round (1980) & 0.6458 & 0.0624 & 1.0786 & 0.0216 & 0.021 \\
Shacham(1980) & 0.6422 & 0.01449 & 0.6421 & $7.04 \mathrm{e}-4$ & 0.0079 \\
Barr (1981) & -0.0653 & 0.0034 & 0.0672 & $5.599 \mathrm{e}-4$ & $7.82 \mathrm{e}-4$ \\
Zigrang- Sylvester (1982) & -0.0566 & 0.0029 & 0.0566 & $-3.72 \mathrm{e}-4$ & 0.0011 \\
Haaland (1983) & -0.0780 & 0.0115 & 0.1467 & 0.0011 & 0.0093 \\
Serghides (1984) & -0.0015 & $8.08 \mathrm{e}-5$ & 0.0015 & $-8.004 \mathrm{e}-6$ & $3.09 \mathrm{e}-5$ \\
Tsal (1989) & -5.2685 & 0.2688 & 5.2829 & 0.0228 & 0.0586 \\
Manadilli (1997) & 0.2058 & 0.0108 & 0.2058 & 0.0028 & $6.85 \mathrm{e}-7$ \\
Monzon et al. (2002) & 0.0442 & 0.0022 & 0.0442 & $5.061 \mathrm{e}-4$ & $-3.89 \mathrm{e}-4$ \\
Goudar-Sonnad (2006) & -0.9319 & 0.0467 & 0.9319 & -0.0087 & 0.0171 \\
Buzzelli (2008) & 0.0118 & $6.07 \mathrm{e}-4$ & 0.0118 & $2.798 \mathrm{e}-4$ & $-7.87 \mathrm{e}-5$ \\
Goudar-Sonnad (2008) & $1.727 \mathrm{e}-9$ & $2.42 \mathrm{e}-9$ & $4.097 \mathrm{e}-9$ & $9.39 \mathrm{e}-10$ & $9.63 \mathrm{e}-10$ \\
Avci and Karagöz(2009) & 0.1752 & 0.0144 & 0.1812 & 0.0098 & $2.48 \mathrm{e}-4$ \\
Papaevangelou (2010) & 0.0088 & 0.0054 & 0.0938 & 0.0015 & 0.002 \\
Brkic1 (2011) & 0.2469 & 0.0123 & 0.2469 & 0.0048 & -0.002 \\
Brkic2 (2011) & -1.8513 & 0.0933 & 1.8513 & -0.0154 & 0.0315 \\
Fang (2011) & 0.10854 & 0.0070 & 0.1096 & 0.0030 & $1.332 \mathrm{e}-4$ \\
Ghanbari et al. (2011) & 1.5568 & 0.0348 & 1.5568 & 0.0162 & -0.0052 \\
\hline & & & & &
\end{tabular}




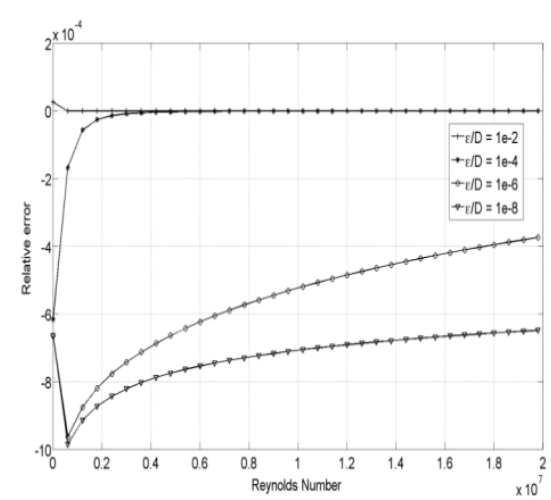

Figure 3. The amount of relative error comparison between the Zigrang- Sylvester and Colebrook White equations.

It is seen that although both graphs have similar trends, the Serghides (1984) correlation with a relative error below $1 \mathrm{e}-5$ is more accurate than the Zigrang \& Sylvester (1982) correlation which has a relative error below $1 \mathrm{e}-4$.

Figure 4 illustrates the relative error comparisons for the Buzzeli (2008) correlation which can be considered to be another good alternative to the Colebrook-White equation. There is a sharp fall in relative error for $\varepsilon / D=1 e-4$, $\varepsilon / \mathrm{D}=1 \mathrm{e}-6$ and $\varepsilon / \mathrm{D}=1 \mathrm{e}-8$ as the Reynolds number approaches the value of $0.056 \mathrm{e} 7$ and then there is a slight change. For $\varepsilon / D=1 e-2$, the relative error remains constant as the Reynolds number increases.

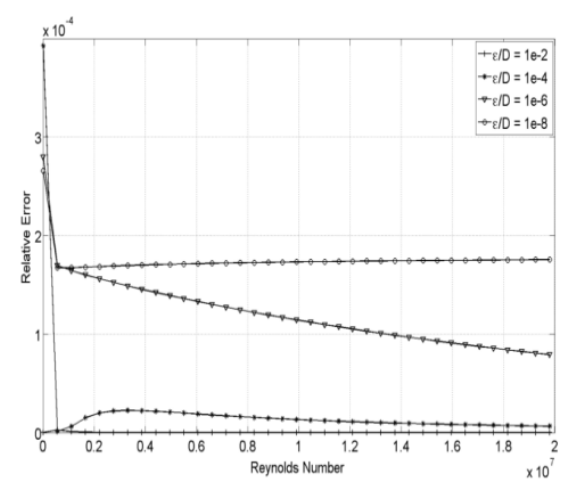

Figure 4. The amount of relative error comparison between the Buzzelli and Colebrook White equations.

Figure 5 shows the relative error of Wood (1966) correlation. For the relative roughness values $\varepsilon / D=1 \mathrm{e}-2$, $\varepsilon / \mathrm{D}=1 \mathrm{e}-4, \varepsilon / \mathrm{D}=1 \mathrm{e}-6$ and $\varepsilon / \mathrm{D}=1 \mathrm{e}-8$. The relative error starts to increase linearly until the Reynolds number value of $0.061 \mathrm{e}$. After that point, there is a slight increase for $\varepsilon / D=1 \mathrm{e}-6$ and $\varepsilon / D=1 \mathrm{e}-8$ as the Reynolds number increases, while for $\varepsilon / D=1 e-4$, there is a slight decrease. For $\varepsilon / D=1 \mathrm{e}-2$ it continues with the constant Reynolds number value.
Table 3 provides the statistical analyses for the relative roughness of $1 \mathrm{e}-$ 4. It is shown that, while the Goudar-Sonnad (2008), Serghides (1984), Zigrang-Sylvester (1979) and Buzzelli (2008) correlations which have a standard deviation of $1.686 \mathrm{e}-9 \%, 7.844 \mathrm{e}-6 \%, 4.32 \mathrm{e}-4$ and $1.351 \mathrm{e}-4 \%$ correspondingly yield reliable results, Altshul (1952) gives the worst predicted values.

Table 3. Statistical comparison for $\varepsilon / D=1 e-4$

\begin{tabular}{llllll}
\hline Correlation & $\begin{array}{l}\text { \% } \\
\text { Average } \\
\text { deviation }\end{array}$ & $\begin{array}{l}\text { \% } \\
\text { Standard } \\
\text { deviation }\end{array}$ & $\begin{array}{l}\text { \% } \\
\text { Mean } \\
\text { deviation }\end{array}$ & MNE & MPE \\
\hline Moody (1947) & 2.640 & 0.1437 & 2.7673 & 0.0341 & 0.0242 \\
Altshul (1952) & -7.8292 & 0.3945 & 7.8437 & 0.0214 & 0.0813 \\
Wood (1966) & 4.077 & 0.2084 & 4.0783 & 0.0561 & 0.0016 \\
Churchill (1973) & 0.3614 & 0.0191 & 0.3652 & 0.0057 & 0.0030 \\
Eck(1973) & -0.8879 & 0.0609 & 0.8957 & 0.0156 & 0.0438 \\
Jain(1976) & 0.3169 & 0.0170 & 0.3242 & 0.0051 & 0.0047 \\
Swamee-Jain (1976) & 0.3939 & 0.0206 & 0.3991 & 0.0059 & 0.0039 \\
Churchill (1977) & 0.3243 & 0.0078 & 0.3243 & 0.0060 & $1.98 \mathrm{e}-4$ \\
Chen (1979) & 0.092 & 0.0059 & 0.0930 & 0.0028 & $2.7 \mathrm{e}-4$ \\
Round (1980) & 7.2818 & 0.3725 & 7.304 & 0.0824 & 0.0154 \\
Shacham(1980) & 0.0262 & 0.0016 & 0.0263 & 0.0050 & $7.93 \mathrm{e}-4$ \\
Barr (1981) & -0.0127 & 0.0014 & 0.0257 & $4.191 \mathrm{e}-4$ & 0.0018 \\
Zigrang-Sylvester (1982) & -0.001 & $4.32 \mathrm{e}-4$ & 0.0019 & $-5.07 \mathrm{e}-8$ & $8.58 \mathrm{e}-4$ \\
Haaland (1983) & -0.1230 & 0.0162 & 0.1796 & $9.429 \mathrm{e}-4$ & 0.0136 \\
Serghides (1984) & $-2.48 \mathrm{e}-5$ & $7.844 \mathrm{e}-6$ & $2.486 \mathrm{e}-5$ & $5.82 \mathrm{e}-10$ & $1.84 \mathrm{e}-5$ \\
Tsal (1989) & 0.9897 & 0.0531 & 1.0148 & 0.0214 & 0.0100 \\
Manadilli (1997) & 0.389 & 0.0206 & 0.3890 & 0.0068 & $-7.4 \mathrm{e}-4$ \\
Monzon et al. (2002) & -0.018 & 0.0011 & 0.0222 & $4.822 \mathrm{e}-4$ & $2.85 \mathrm{e}-4$ \\
Goudar-Sonnad (2006) & -1.1196 & 0.0560 & 1.1196 & -0.0109 & 0.0172 \\
Buzzelli (2008) & 0.0015 & $1.351 \mathrm{e}-4$ & 0.0015 & 3.9278 & $-1.63 \mathrm{e}-8$ \\
Goudar-Sonnad (2008) & $-1.447 \mathrm{e}-9$ & $1.686 \mathrm{e}-9$ & $2.92 \mathrm{e}-8$ & $5.88 \mathrm{e}-10$ & $5.961 \mathrm{e}-10$ \\
Avci and Karagöz(2009) & -0.4401 & 0.0224 & 0.4463 & 0.0041 & 0.0046 \\
Papaevangelou (2010) & 0.0339 & 0.007 & 0.1218 & 0.0036 & 0.0014 \\
Brkic1 (2011) & 0.3619 & 0.0198 & 0.3619 & 0.0074 & -0.0017 \\
Brkic2 (2011) & -0.0444 & 0.0161 & 0.1234 & $5.85 \mathrm{e}-4$ & 0.0303 \\
Fang (2011) & 0.0121 & 0.0067 & 0.1081 & 0.0013 & 0.0038 \\
Ghanbari et al. (2011) & 0.4292 & 0.0109 & 0.4292 & 0.0104 & -0.0017 \\
\hline
\end{tabular}

Table 4 provides the information corresponding to $\varepsilon / D=1 \mathrm{e}-2$. The Goudar \& Sonnad (2008), Serghides (1984), Buzzelli (2008) and Zigrang \& Sylvester (1979) correlations resulted with satisfactory results and can be utilized instead of the Colebrook-White equation for this relative roughness value. Results obtained for the lower relative roughness of $\varepsilon / D=1 e-2$ are more accurate than the results for the higher relative roughness of $\varepsilon / D=1 e$ 8 , with $\varepsilon / D=1 e-6$ and $\varepsilon / D=1 e-4$ being the values for all correlations.

Table 4. Statistical comparison for $\varepsilon / D=1 e-2$

\begin{tabular}{llllll}
\hline Correlation & $\begin{array}{l}\text { \% } \\
\text { Average } \\
\text { deviation }\end{array}$ & $\begin{array}{l}\text { \% } \\
\text { Standard } \\
\text { deviation }\end{array}$ & $\begin{array}{l}\text { \% } \\
\text { Mean } \\
\text { deviation }\end{array}$ & MNE & MPE \\
\hline Moody (1947) & -0.6558 & 0.0329 & 0.6558 & -0.0064 & 0.0188 \\
Altshul (1952) & -8.225 & 0.4112 & 8.225 & -0.0812 & 0.0822 \\
Wood (1966) & 1.9757 & 0.0989 & 1.9789 & 0.0198 & 0.0179 \\
Churchill (1973) & -0.0408 & 0.0068 & 0.0758 & 0.0210 & $7.987 \mathrm{e}-4$ \\
Eck(1973) & -0.0761 & 0.0077 & 0.0922 & 0.0257 & $8.988 \mathrm{e}-4$ \\
Jain(1976) & -0.0923 & 0.0077 & 0.1158 & 0.0197 & 0.0012 \\
Swamee-Jain (1976) & 0.0444 & 0.0066 & 0.0444 & 0.0212 & $-1.124 \mathrm{e}-4$ \\
Churchill (1977) & -0.0226 & 0.0017 & 0.0471 & 0.01011 & $4.982 \mathrm{e}-4$ \\
Chen (1979) & -0.056 & 0.0029 & 0.0575 & 0.0016 & $5.896 \mathrm{e}-4$ \\
Round (1980) & -1.1257 & 0.0563 & 1.125 & -0.0112 & 0.0175 \\
Shacham(1980) & $-1.08 \mathrm{e}-4$ & $6.36 \mathrm{e}-5$ & $1.08 \mathrm{e}-4$ & $3.5 \mathrm{e}-10$ & 0.0012 \\
Barr (1981) & -0.0172 & 0.0012 & 0.0179 & 0.0013 & $9.53 \mathrm{e}-4$ \\
Zigrang- Sylvester (1982) & $6.495 \mathrm{e}-6$ & $6.473 \mathrm{e}-6$ & $6.536 \mathrm{e}-6$ & $2.589 \mathrm{e}-5$ & $7.604 \mathrm{e}-10$ \\
Haaland (1983) & 0.1956 & 0.0098 & 0.1965 & 0.0019 & 0.0018 \\
Serghides (1984) & $-2.52 \mathrm{e}-9$ & $2.217 \mathrm{e}-9$ & $3.84 \mathrm{e}-8$ & $7.6696 \mathrm{e}-10$ & $7.604 \mathrm{e}-10$ \\
Tsal (1989) & -8.2253 & 0.4112 & 8.225 & -0.0812 & 0.0822 \\
Manadilli (1997) & 0.0448 & 0.0066 & 0.0448 & 0.020 & $-1.047 \mathrm{e}-4$ \\
Monzon et al. (2002) & -0.0587 & 0.0029 & 0.0587 & $4.10 \mathrm{e}-5$ & $5.926 \mathrm{e}-4$ \\
Goudar-Sonnad (2006) & -1.9046 & 0.0952 & 1.9046 & -0.019 & 0.0207 \\
Buzzelli (2008) & $3.6797 \mathrm{e}-5$ & $9.97 \mathrm{e}-6$ & $3.679 \mathrm{e}-5$ & $2.897 \mathrm{e}-5$ & $-1.28 \mathrm{e}-8$ \\
Goudar-Sonnad (2008) & $-2.487 \mathrm{e}-9$ & $2.218 \mathrm{e}-9$ & $3.85 \mathrm{e}-8$ & $7.669 \mathrm{e}-10$ & $7.604 \mathrm{e}-10$ \\
Avci and Karagöz (2009) & -1.20237 & 0.0601 & 1.2023 & -0.0119 & $4.98 \mathrm{e}-4$ \\
Papaevangelou (2010) & -0.0241 & 0.0019 & 0.0349 & 0.0021 & $4.51 \mathrm{e}-4$ \\
Brkic1 (2011) & -0.0449 & 0.0071 & 0.0780 & 0.0214 & $8.073 \mathrm{e}-4$ \\
Brkic2 (2011) & -0.0604 & 0.0043 & 0.0747 & 0.0063 & $8.325 \mathrm{e}-4$ \\
Fang (2011) & 0.06443 & 0.0032 & 0.0645 & $9.63 \mathrm{e}-4$ & $2.96 \mathrm{e}-4$ \\
Ghanbari et al. (2011) & -0.2109 & 0.0048 & 0.2145 & 0.0053 & 0.0023 \\
\hline & & & & & \\
\hline
\end{tabular}




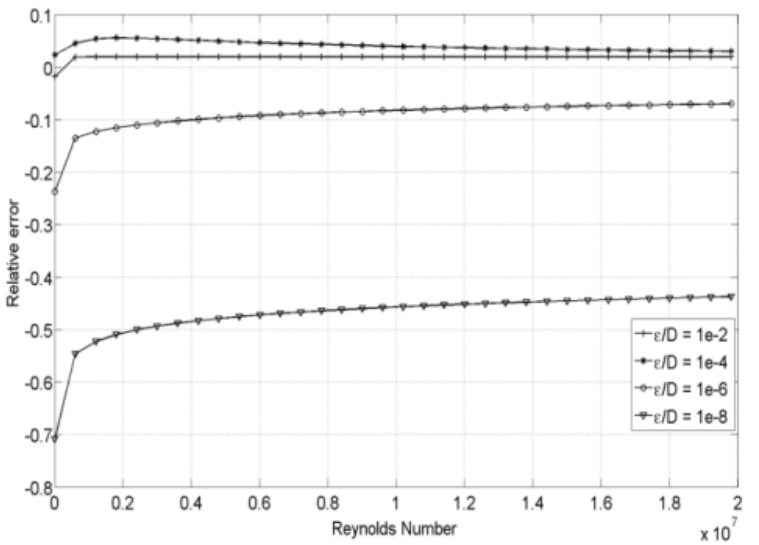

Figure 5. The amount of relative error comparison between the Wood and Colebrook White equations.

Figure 6 shows the relative error of the Altshul (1947) correlation. Relative error decreases for $\varepsilon / D=1 e-4$, $\varepsilon / \mathrm{D}=1 \mathrm{e}-6$ and $\varepsilon / \mathrm{D}=1 \mathrm{e}-8$ with the increase of the Reynolds number. However, for $\varepsilon / D=1 \mathrm{e}-2$, the relative error value stays constant with increasing Reynolds number.

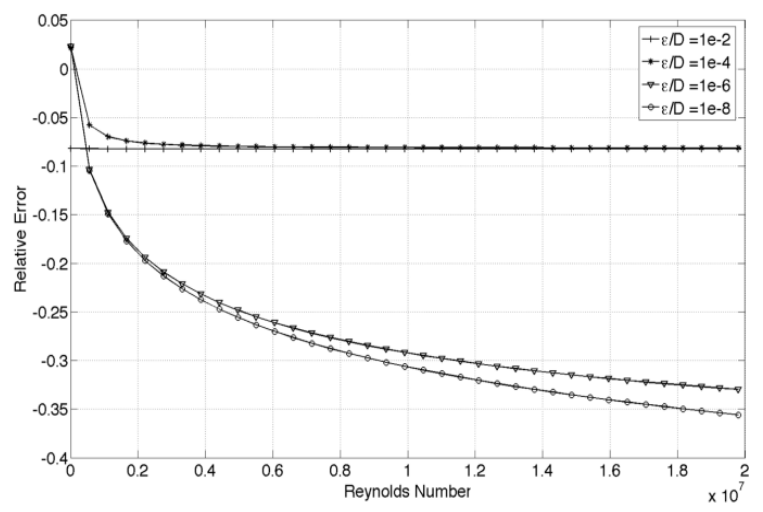

Figure 6. The amount of relative error comparison between the Altshul and Colebrook White equations.

Figure 7 shows the relative error of the Tsal (1989) correlation. Relative error decreases for $\varepsilon / D=1 \mathrm{e}-6$ and $\varepsilon / D=1 e-8$ with the increase of the Reynolds number while for $\varepsilon / D=1 \mathrm{e}-4$ it increases slightly. However, for $\varepsilon / D=1 e-2$, the relative error value stays constant with the increasing Reynolds number.

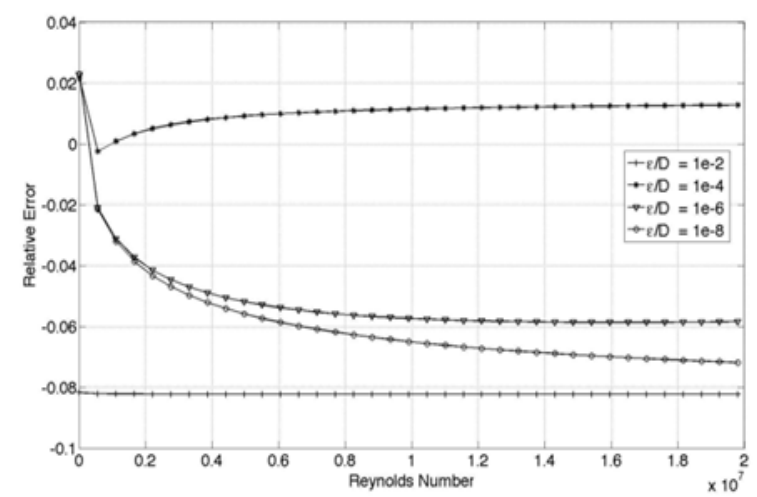

Figure 7. The amount of relative error comparison between the Tsal and Colebrook White equations.

\section{Conclusion}

Results gained from error analysis are briefly explained below. If the approximation formulas are scaled in the order of relative error, best results are obtained from the Goudar \& Sonnad (2008) and Serghides (1984) correlations. The worst results are gained from the Altshul (1952) and Wood (1966) correlations.

When a comparison is made according to the degree of the relative error, the Goudar \& Sonnad (2008) correlation with an error percentage $10^{-9} \%$ is very close to the result obtained from the Colebrook-White equation. Then the next best equation is achieved by the Serghides (1984) correlation with an error percentage of $10^{-4} \%$ which can also be used practically.

Because of the high precision of the selected correlations, the need for using the Colebrook-White iterative solution seems to be eliminated.

\section{References}

Barr DIH (1981). Solutions of the Colebrook-White functions for resistance to uniform turbulent flows. Proc Inst Civil Eng 71, 529-536.

Brkic D (2011). An explicit approximation of the Colebrook equation for fluid flow friction factor. Petrol Sci Tech 29, 1596-1602.

Buzzelli D (2008). Calculating friction in one step. Mach Des, 80, 54-55.

Chen NH (1979). An explicit equation for friction factor in Pipe. Ind. Eng Chem Fund 18, 296-297.

Churchill, SW (1973). Empirical expressions for the shear stress in turbulent flow in commercial pipe. AIChE J 19, 375-376.

Churchill SW (1977). Friction factor equation spans all fluid-flow ranges. Chem Eng 84, 91-92.

Colebrook CF, White CM (1937). Experiments with fluid friction roughened pipes. Proc R Soc (A), 161.

Clamond D (2009). Efficient resolution of the Colebrook equation. Ind Eng Chem Res 48, 3665-3671.

Eck B (1973). Technische Stromungslehre. Springer, New York.

Fang X, Xua Y, Zhou Z (2011). New correlations of singlephase friction factor for turbulent pipe flow and evaluation of existing single-phase friction factor correlations. Nucl Eng Des 241, 897-902.

Genić S, Arandjelović I, Kolendić P, Jsrić M, Budimir N (2011). A review of explicit approximations of Colebrook's equation. FME Trans 39, 67-71.

Ghanbari A, Farshad F, Rieke HH (2011). Newly developed friction factor correlation for pipe flow and flow assurance. J Chem Eng Mat Sci 2, 83-86.

Goudar CT, Sonnad JR (2008). Comparison of the iterative approximations of the Colebrook-White equation. Hydrocarb Process 87, 79-83

Haaland SE (1983). Simple and Explicit formulas for friction factor in turbulent pipe flow. J Fluid Eng ASME 105, 89-90.

Jain AK (1976). Accurate explicit equation for friction factor. J Hydraul Div Am Soc Civ Eng 102, 674-677.

Manadilli G (1997). Replace implicit equations with signomial functions. Chem Eng 104, 129-132.

Moody LF (1947). An approximate formula for pipe friction factors. Trans ASME 69, 1005-1006. 
Papaevangelou G, Evangelides C, Tzimopoulos C (2010). A new explicit relation for friction coefficient in the Darcy-Weisbach equation. Proceedings of the Tenth Conference on Protection and Restoration of the Environment 166,1-7pp, PRE10 July 6-09 2010 Corfu, Greece.

Romeo E, Royo C, Monzón A (2002). Improved explicit equations for estimation of the friction factor in rough and smooth pipes. Chem Eng J 86, 369-374.

Round, GF (1980). An explicit approximation for the friction factor-Reynolds number relation for rough and smooth pipes. Can J Chem Eng 58, 122-123.

Samadianfard S (2012). Gene expression programming analysis of implicit Colebrook-White equation in turbulent flow friction factor calculation. J Petrol Sci Eng 92, 48-55.

Serghides TK (1984). Estimate friction factor accurately. Chem Eng 91, 63-64.

Shacham M (1980). An explicit equation for friction factor in pipe. Ind Eng Chem Fund 19, 228 - 229.

Sonnad JR, Goudar CT (2006). Turbulent flow friction factor calculation using a mathematically exact alternative to the Colebrook-White equation. J Hydraul Eng 132, 863-867.

Swamee PK, Jain AK (1976). Explicit equation for pipe flow problems. J Hydr Div ASCE 102, 657-664.

Tsal RJ (1989). Altshul-Tsal friction factor equation. Heating Piping Air Conditioning 8, 30-45.

Winning HK, Coole T (2013). Explicit friction factor accuracy and computational efficiency for turbulent flow in pipes. Flow Turbulence Combust 90, 1-27.

White F (2001). Fluid Mechanics. Fourth edition. Published by McGraw-Hill, New York ISBN 0-07069716-7.

Wood DJ (1966). An explicit friction factor relationship. Civil Eng 60-61.

Zigrang DJ, Sylvester ND (1982). Explicit approximations to the Colebrook's friction factor. AICHE J 28, 514-515. 